Mistiaen, P.J., Jolley, D.J., McGowan, S., Hickey, M.B., Spreeuwenberg, P., Francke, A.L. A multilevel analysjs of three randomised controlled trials of the Australian Medical Sheepskin in the prevention of sacral pressyr ulcers. Medical Journal of Australia: 2010, 193(11/12), 638-641

\begin{tabular}{|l|l|}
\hline Postprint Version & 1.0 \\
\hline Journal website & http://www.mja.com.au/public/issues/193_11_061210/mis10295_fm.html \\
\hline Pubmed link & http://www.ncbi.nlm.nih.gov/pubmed/21143048 \\
\hline DOI &
\end{tabular}

This is a NIVEL certified Post Print, more info at http://www.nivel.eu

\title{
A multilevel analysis of three randomised controlled trials of the Australian Medical Sheepskin in the prevention of sacral pressure ulcers
}

\author{
Patriek J Mistiaen ${ }^{1}$, DAmien J Jolley ${ }^{2}$, Sunita McGowan ${ }^{34}$, MARK B HickeY ${ }^{5}$, Peter \\ SPREEUWENBERG ${ }^{1}$ AND ANNEKE L FRANCKE ${ }^{16}$ \\ 1 NIVEL - Netherlands Institute for Health Services Research, Utrecht, The Netherlands. \\ 2 School of Public Health and Community Medicine, Melbourne, VIC. \\ 3 Fremantle Hospital, Fremantle, WA. \\ 4 Curtin University, Perth, WA. \\ 5 CSIRO Materials Science and Engineering, Melbourne, VIC. \\ 6 Department of Public and Occupational Health, EMGO+ Institute for Health and Care Research, VU \\ University Medical Center, Amsterdam, The Netherlands.
}

\begin{abstract}
Objective: To assess the effectiveness of the Australian Medical Sheepskin in preventing sacral pressure ulcers (PUs), based on combined data from existing published trials.

Design and setting: Data from two randomised controlled trials (RCTs) among Australian hospital patients and one RCT among Dutch nursing home patients were pooled, comprising a total population of 1281 patients from 45 nursing wards in 11 institutions. These data were analysed in two ways: with conventional meta-analysis based on the published effect sizes; and with multilevel binary logistic regression based on the combined individual patient data. In the multilevel analysis, patient, nursing ward and institution were used as levels and we controlled for sex, age, PU risk and number of days of observation.

Main outcome measure: Incidence of sacral PUs.

Results: Overall, the incidence of sacral PUs was $12.2 \%$ in the control group versus $5.4 \%$ in the intervention group with an Australian Medical Sheepskin. Conventional meta-analysis showed significantly reduced odds of developing a PU while using the sheepskin (odds ratio [OR], 0.37 [95\% CI, 0.17-0.77]). Multilevel analysis gave an OR of 0.35 and narrowed the confidence interval by almost $50 \%(95 \% \mathrm{CI}, 0.23-0.55)$.

Conclusions: These analyses of pooled data confirm that the Australian Medical Sheepskin is effective in preventing sacral PUs. Multilevel analysis of individual patient data gives a more precise effect estimate than conventional meta-analysis.
\end{abstract}

Pressure ulcers (PUs) are a highly prevalent problem. ${ }^{1,2}$ They have a large impact on quality of life $\mathrm{e}^{3,4}$ and high costs are involved in treatment. ${ }^{5-7}$ There is a lack of knowledge about the effectiveness and costeffectiveness of many of the devices that help prevent PUs. ${ }^{8,9}$ One such preventive device is the sheepskin. Sheepskins were commonly used in the past, but due to poor product specification and inferior manufacturing practices, combined with the influx of synthetic, imitation products, the use of genuine 
Mistiaen, P.J., Jolley, D.J., McGowan, S., Hickey, M.B., Spreeuwenberg, P., Francke, A.L. A multilevel analys js of three randomised controlled trials of the Australian Medical Sheepskin in the prevention of sacral pressyre ulcers. Medical Journal of Australia: 2010, 193(11/12), 638-641

sheepskins declined. Poorly manufactured natural sheepskins were difficult to launder and did not meet infection-control standards; synthetic sheepskins were found to have little pressure-relieving capacity. ${ }^{10,11}$

The Commonwealth Scientific and Industrial Research Organisation (CSIRO) renewed interest in the natural product and in 1998 introduced the Australian Medical Sheepskin, specified by the Australian Standard AS4480.1-1998. ${ }^{12}$ This sheepskin is capable of withstanding repeated washing at $80^{\circ} \mathrm{C}$, satisfying infection-control requirements. ${ }^{13}$ Its dense, $25 \mathrm{~mm}$ natural wool pile reduces pressure, shear and friction forces, and has the capacity to absorb moisture away from the patient's skin. Its effectiveness has been studied in two randomised controlled trials (RCTs) in hospital patients $1^{4,15}$ (in 2000 and 2004) and in a recent RCT in nursing homes (in 2009). ${ }^{16}$

We aimed to estimate the overall effectiveness of the Australian Medical Sheepskin in preventing sacral PUs across these three RCTs, using two methods: first, conventional meta-analysis of the pooled published effect sizes; and second, multilevel analysis of the combined individual patient data, which should give a more reliable and informative estimate of the effect size. ${ }^{17,18}$

\section{METHODS}

Selection of the three trials used for the combined analysis was based on the search results of two systematic reviews, ${ }^{9,19}$ complemented by an additional recent trial known to us. ${ }^{16}$ The characteristics of the three trials are described in Box 1.

\section{[BOX 1]}

To enable us to pool the results, we identified the common interventions and outcomes. In all three trials, patients were randomly allocated to either use of an Australian Medical Sheepskin overlay in their beds, or usual care with a standard mattress. While both Australian trials used the incidence of any PUs, the Dutch trial used the incidence of sacral PUs only. We therefore analysed the effect of the sheepskin only on the incidence of sacral PUs; we considered the three trials to be sufficiently comparable to allow this analysis. Severity of ulcers was categorised in the three trials according to comparable four-grade systems. The length of follow-up in the hospital trials was until discharge from hospital, and in the nursing home trial, to 30 days after admission or until discharge (whichever came first).

Differences in patient characteristics (PU risk, age, and hospital or nursing ward) between the trials were taken into account in the analyses.

We contacted the study authors and asked for permission to use their individual patient data and, if they consented, to send the original (de-identified) data of all patients for whom a completed record was obtained. Datasets were standardised by giving common variables the same names, and basic frequency analyses were performed and checked against the published results. The standardised datasets were sent to the study authors for verification that the process had been applied correctly, before being merged into one dataset of only those variables used in all three trials. The combined data were again sent to the study authors for a final check that the merging process had been performed correctly.

A conventional meta-analysis was performed on the pooled published effect sizes from each trial using the Mantel-Haenszel method with a random effects model, computed using Review Manager, version 5.0, 2008 (Nordic Cochrane Centre, Cochrane Collaboration, Copenhagen, Denmark).

Multilevel binary logistic regression analysis was performed on the individual patient data using MLwiN, version 2.02, 2005 (Centre for Multilevel Modelling, University of Bristol, Bristol, UK), with three nested levels: patients within wards within institutions. The independent variable was the allocated group; the dependent variable was the incidence of sacral PUs during the period of observation. We controlled for age, sex, number of days of observation and the PU risk at admission (measured with the Braden scale in all three $\mathrm{RCTs}^{20}$ ). Multilevel analyses were done for the three trials separately and for the combined dataset. The results are expressed as odds ratios with $95 \%$ confidence intervals.

Risk of bias in the studies was assessed on five aspects as published in the two systematic reviews ${ }^{9,19}$ for the two Australian trials, and on our own judgement for the Dutch trial (Box 2). 
Mistiaen, P.J., Jolley, D.J., McGowan, S., Hickey, M.B., Spreeuwenberg, P., Francke, A.L. A multilevel analysjs of three randomised controlled trials of the Australian Medical Sheepskin in the prevention of sacral pressyre ulcers. Medical Journal of Australia: 2010, 193(11/12), 638-641

\section{[BOX 2]}

Ethics approval had been obtained for each of the trials. Permission to pool the data was obtained from the primary authors and their managers. All individual patient data were de-identified.

\section{RESULTS}

The total population consisted of 1281 patients from 11 institutions and involved 45 nursing wards. The three combined RCTs covered more than 20000 observation days. The mean observation length was about 17 days, varying from about 7 and 11 in the hospital trials to 28 in the nursing home trial. Intervention and control groups were comparable in the separate trials and in the combined dataset with respect to age, sex, PU risk and number of observation days. The main characteristics of the patients in the individual studies and in the total group are shown in Box 3.

\section{[BOX 3]}

The overall incidence of sacral PUs in the three trials was 5.4\% (35 PUs) in the intervention group versus $12.2 \%$ ( $78 \mathrm{PUs}$ ) in the control group (bivariate $\chi 2, \mathrm{P}<0.001$ ). The relative risk reduction was $56 \%(95 \%$ CI, 35\%-70\%). Of the 113 newly acquired sacral PUs, 92 (81\%) were grade 1 (least severe), 19 (17\%) were grade 2 , and $2(2 \%)$ were grade 3 .

The conventional meta-analysis showed an odds ratio for developing a grade $1-4$ sacral PU during the period of observation while using a sheepskin of 0.37 (95\% CI, 0.17-0.77; heterogeneity, I2 =59\%), compared with no sheepskin. The multilevel logistic regression analysis showed an odds ratio of 0.35 (95\% CI, 0.23-0.55). The results of both analyses are shown in Box 4 and Box 5.

\section{[BOX 4] [BOX 5]}

\section{DISCUSSION}

Conventional meta-analysis of effect sizes for the three trials demonstrated that the Australian Medical Sheepskin was effective in preventing sacral PUs, with an odds ratio of 0.37 . The multilevel analysis on the combined individual patient data resulted in an odds ratio of 0.35 , confirming that the Australian Medical Sheepskin is effective. Using individual patient data gave a confidence interval almost $50 \%$ smaller than that from the conventional meta-analysis, and hence a more precise effect estimate. Moreover, multilevel analysis of individual patient data is preferred because it can take patient and ward characteristics into account.

Although both approaches give an overall effect estimate, both remain liable to risk of bias in the trials, for instance due to inadequate allocation concealment or suboptimal outcome assessment. Furthermore, although the risk of bias of the underlying studies was assessed as much as possible on judgements from published systematic reviews, there might still be a bias in the pooled analysis because we were all also coauthors of the pooled studies.

In line with earlier studies, our results have shown that the Australian Medical Sheepskin is an effective aid in preventing PUs. ${ }^{9,19}$ However, further research about the effectiveness of the Australian Medical Sheepskin is still needed. All three trials involved short observation periods, and this can be a critical stage, as it is known that many PUs develop when patients are relatively immobile, ${ }^{21}$ and most PUs in nursing homes develop within the first 3 weeks after admission. ${ }^{22}$ How good the Australian Medical Sheepskin is in preventing PUs in patients confined to bed for longer terms is still unknown. Research involving larger sample sizes is also needed to study its effect in the prevention of higher grade PUs. In practice, the Australian Medical Sheepskin is an effective option for use in the prevention of pressure ulcers, and our findings suggest that guidelines need no longer discourage its use. 
Mistiaen, P.J., Jolley, D.J., McGowan, S., Hickey, M.B., Spreeuwenberg, P., Francke, A.L. A multilevel analys js of three randomised controlled trials of the Australian Medical Sheepskin in the prevention of sacral pressyre ulcers. Medical Journal of Australia: 2010, 193(11/12), 638-641

\section{REFERENCES}

Horn SD, Bender SA, Ferguson ML, et al. The National Pressure Ulcer Long-Term Care Study: pressure ulcer development in long-term care residents. J Am Geriatr Soc 2004; 52: 359-367.

Vangilder C, Macfarlane GD, Meyer S. Results of nine international pressure ulcer prevalence surveys: 1989 to 2005. Ostomy Wound Manage 2008; 54: 40-54.

Essex HN, Clark M, Sims J, et al. Health-related quality of life in hospital inpatients with pressure ulceration: assessment using generic health-related quality of life measures. Wound Repair Regen 2009; 17: 797805.

Gorecki C, Brown JM, Nelson EA, et al. Impact of pressure ulcers on quality of life in older patients: a systematic review. J Am Geriatr Soc 2009; 57: 1175-1183.

Severens JL, Habraken JM, Duivenvoorden S, Frederiks CM. The cost of illness of pressure ulcers in The Netherlands. Adv Skin Wound Care 2002; 15: 72-77.

Bennett G, Dealey C, Posnett J. The cost of pressure ulcers in the UK. Age Ageing 2004; 33: 230-235.

Schuurman JP, Schoonhoven L, Defloor T, et al. Economic evaluation of pressure ulcer care: a cost minimization analysis of preventive strategies. Nurs Econ 2009; 27: 390-400.

Reddy M, Gill SS, Rochon PA. Preventing pressure ulcers: a systematic review. JAMA 2006; 296: 974-984.

McInnes E, Bell-Syer SE, Dumville JC, et al. Support surfaces for pressure ulcer prevention. Cochrane Database Syst Rev 2008; (4): CD001735.

Marchand AC, Lidowski H. Reassessment of the use of genuine sheepskin for pressure ulcer prevention and treatment. Decubitus 1993; 6: 44-47.

Defloor T, Grypdonck MH. Do pressure relief cushions really relieve pressure? West J Nurs Res 2000; 22: 335-350.

Standards Australia. Australian Standard 4480.1. Textiles for health care facilities and institutions medical sheepskin. Sydney: Standards Association of Australia, 1998.

Commonwealth Scientific and Industrial Research Organisation. Australian medical sheepskins: an Australian gift to medicine. Melbourne: CSIRO, 2001.

McGowan S, Montgomery KC, Jolley DJ, Wright R. The role of sheepskins in preventing pressure ulcers in elderly orthopaedic patients. Primary Intention 2000; 8: 127-134.

Jolley DJ, Wright R, McGowan S, et al. Preventing pressure ulcers with the Australian Medical Sheepskin: an open-label randomised controlled trial. Med J Aust 2004; 180: 324-327.

Mistiaen P, Achterberg W, Ament A, et al. The effectiveness of the Australian Medical Sheepskin for the prevention of pressure ulcers in somatic nursing home patients: a prospective multicenter randomizedcontrolled trial (ISRCTN17553857). Wound Repair Regen 2010; 18: 572-579.

Stewart LA, Tierney JF. To IPD or not to IPD? Advantages and disadvantages of systematic reviews using individual patient data. Eval Health Prof 2002; 25: 76-97.

Cooper $\mathrm{H}$, Patall EA. The relative benefits of meta-analysis conducted with individual participant data versus aggregated data. Psychol Methods 2009; 14: 165-176.

Medical Advisory Secretariat. Pressure ulcer prevention: an evidence-based analysis. Ont Health Technol Assess Ser 2009; 9 (2): 1-104.

Bergstrom N, Braden BJ, Laguzza A, Holman V. The Braden Scale for predicting pressure sore risk. Nurs Res 1987; 36: 205-210.

Baumgarten M, Margolis DJ, Orwig DL, et al. Pressure ulcers in elderly patients with hip fracture across the continuum of care. J Am Geriatr Soc 2009; 57: 863-870.

van Marum RJ, Ooms ME, Ribbe MW, van Eijk JT. The Dutch pressure sore assessment score or the Norton scale for identifying at-risk nursing home patients? Age Ageing 2000; 29: 63-68. 
Mistiaen, P.J., Jolley, D.J., McGowan, S., Hickey, M.B., Spreeuwenberg, P., Francke, A.L. A multilevel analysjs of three randomised controlled trials of the Australian Medical Sheepskin in the prevention of sacral pressyre ulcers. Medical Journal of Australia: 2010, 193(11/12), 638-641

1 Characteristics of the three randomised controlled trials of the effectiveness of the Australian Medical Sheepskin analysed in this study

\begin{tabular}{|c|c|c|c|}
\hline & McGowan $2000^{14}$ & Jolley $2004^{15}$ & Mistiaen $2010^{16}$ \\
\hline \multirow[t]{3}{*}{ Inclusion criteria } & Admitted with an orthopaedic diagnosis & Admitted to one of the hospital wards & $\begin{array}{l}\text { Admitted to one of the wards for a } \\
\text { primarily medical reason }\end{array}$ \\
\hline & Age $\geqslant 60$ years & Age $\geqslant 18$ years & Age $\geq 18$ years \\
\hline & $\begin{array}{l}\text { Low or moderate risk of developing } \\
\text { a pressure ulcer (Braden } \mathrm{scale}^{20} \text { ) }\end{array}$ & $\begin{array}{l}\text { Low or moderate risk of developing } \\
\text { a pressure ulcer (Braden scale }{ }^{20} \text { ) }\end{array}$ & \\
\hline \multirow[t]{4}{*}{ Exclusion criteria } & A pressure ulcer on admission & A pressure ulcer on admission & A pressure ulcer on admission \\
\hline & Anticipated stay $<48 \mathrm{~h}$ & Anticipated stay $<48 \mathrm{~h}$ & Anticipated stay $<1$ week \\
\hline & Patients with darkly pigmented skin & Patients with darkly pigmented skin & Patients with darkly pigmented skin \\
\hline & No risk or high risk for pressure ulcers & No risk or high risk for pressure ulcers & \\
\hline Institutions & Two Australian hospitals & One Australian hospital & Eight Dutch nursing homes \\
\hline Nursing wards & Four orthopaedic wards & $\begin{array}{l}18 \text { nursing wards (all types of medical } \\
\text { and surgical specialty) }\end{array}$ & 23 nursing wards (mainly rehabilitation) \\
\hline \multirow[t]{2}{*}{ Intervention } & $\begin{array}{l}\text { Usual care with standard hospital } \\
\text { mattress and an Australian Medical } \\
\text { Sheepskin overlay on the bed }\end{array}$ & $\begin{array}{l}\text { Usual care with standard hospital } \\
\text { mattress and an Australian Medical } \\
\text { Sheepskin overlay on the bed }\end{array}$ & $\begin{array}{l}\text { Usual care with standard hospital mattress } \\
\text { and an Australian Medical Sheepskin } \\
\text { overlay on the bed }\end{array}$ \\
\hline & $\begin{array}{l}\text { Sheepskin heel and elbow protectors } \\
\text { if required }\end{array}$ & $\begin{array}{l}\text { Sheepskin heel and elbow protectors } \\
\text { if required }\end{array}$ & Sheepskin under heels or in chair allowed \\
\hline Control condition & \multicolumn{3}{|c|}{ Usual care with standard hospital mattress Usual care with standard hospital mattress Usual care with standard hospital mattress } \\
\hline \multicolumn{4}{|c|}{ Outcome } \\
\hline Type of ulcer & $\begin{array}{l}\text { Incidence of all kinds of pressure ulcers } \\
\text { (all grades) }\end{array}$ & $\begin{array}{l}\text { Incidence of all kinds of pressure ulcers } \\
\text { (all grades) }\end{array}$ & $\begin{array}{l}\text { Incidence of sacral pressure ulcers } \\
\text { (all grades) }\end{array}$ \\
\hline Assessment & $\begin{array}{l}\text { Daily visual inspection of the skin by } \\
\text { nurse; regular checks by primary } \\
\text { investigator }\end{array}$ & $\begin{array}{l}\text { Daily visual inspection of the skin by } \\
\text { nurse; regular checks by primary } \\
\text { investigator }\end{array}$ & $\begin{array}{l}\text { Daily visual inspection of the skin by } \\
\text { nurse; regular checks by primary } \\
\text { investigator }\end{array}$ \\
\hline \multirow[t]{2}{*}{ Study endpoint } & $\begin{array}{l}\text { Discharge (including dying) or } \\
\text { transfer to other ward or institution }\end{array}$ & $\begin{array}{l}\text { Discharge (including dying) or } \\
\text { transfer to other ward or institution }\end{array}$ & $\begin{array}{l}\text { Discharge (including dying) or transfer } \\
\text { to other ward or institution or } 30 \text { days } \\
\text { after admission }\end{array}$ \\
\hline & Became high risk & Became high risk & \\
\hline
\end{tabular}

2 Assessment of the risk of bias in the three randomised controlled trials (RCTs) analysed in this study, according to two reviews and our own judgement

\begin{tabular}{|c|c|c|c|c|c|}
\hline \multirow[b]{2}{*}{ Aspect of trial } & \multicolumn{2}{|c|}{ McGowan $2000^{14}$} & \multicolumn{2}{|c|}{ Jolley $2004^{15}$} & \multirow{2}{*}{$\frac{\text { Mistiaen } 2010^{16}}{\text { Own judgement }}$} \\
\hline & 2008 review $^{9}$ & 2009 review $^{19}$ & 2008 review $^{9}$ & 2009 review $^{19}$ & \\
\hline Designed as RCT & No & Yes & Yes & Yes & Yes \\
\hline $\begin{array}{l}\text { Concealed } \\
\text { allocation }\end{array}$ & Unclear & Yes & Yes & Yes & Yes \\
\hline $\begin{array}{l}\text { Sample size } \\
\text { calculation }\end{array}$ & Yes & Yes & Unclear & Yes & Yes \\
\hline $\begin{array}{l}\text { Blinded outcome } \\
\text { assessment }\end{array}$ & No & No & No & No & No \\
\hline $\begin{array}{l}\text { Intention-to-treat } \\
\text { analysis }\end{array}$ & $\begin{array}{l}\text { Not stated } \\
\text { in review }\end{array}$ & No & No & Yes & Yes \\
\hline
\end{tabular}


Mistiaen, P.J., Jolley, D.J., McGowan, S., Hickey, M.B., Spreeuwenberg, P., Francke, A.L. A multilevel analys js of three randomised controlled trials of the Australian Medical Sheepskin in the prevention of sacral pressyt ulcers. Medical Journal of Australia: 2010, 193(11/12), 638-641

3 Main characteristics of patients in the three randomised controlled trials of the Australian Medical Sheepskin analysed in this study, by allocated group

\begin{tabular}{|c|c|c|c|c|}
\hline Patient characteristic & Study & Intervention group & Control group & $P$ \\
\hline \multirow{4}{*}{$\begin{array}{l}\text { Number included in } \\
\text { analysis (number } \\
\text { undergoing } \\
\text { randomisation) }\end{array}$} & McGowan $2000^{14}$ & 155 (155) & $142(142)$ & \\
\hline & Jolley $2004^{15}$ & $218(270)$ & 223 (269) & \\
\hline & Mistiaen $2010^{16}$ & $271(295)$ & $272(293)$ & \\
\hline & Pooled data & $644(720)$ & $637(704)$ & 0.75 \\
\hline \multirow{4}{*}{$\begin{array}{l}\text { Mean age, years } \\
\text { (median [range]) }\end{array}$} & McGowan 2000 & 73.7 (74 [60-97]) & $74.0(74$ [60-96]) & \\
\hline & Jolley 2004 & 63.2 (68 [18-97]) & 61.1 (64 [18-99]) & \\
\hline & Mistiaen 2010 & 78.5 (80 [26-97]) & 78.3 (81 [28-98]) & \\
\hline & Pooled data & 72.1 (75 [18-97]) & 71.3 (75 [18-99]) & 0.33 \\
\hline \multirow[t]{4}{*}{ Sex, \% female } & McGowan 2000 & $53.5 \%$ & $61.3 \%$ & \\
\hline & Jolley 2004 & $48.6 \%$ & $51.6 \%$ & \\
\hline & Mistiaen 2010 & $72.0 \%$ & $66.5 \%$ & \\
\hline & Pooled data & $59.6 \%$ & $60.1 \%$ & 0.86 \\
\hline \multirow{4}{*}{$\begin{array}{l}\text { Pressure ulcer risk, } \\
\text { mean Braden scale } \\
\text { score }^{20}\end{array}$} & McGowan 2000 & 13.9 & 14.0 & \\
\hline & Jolley 2004 & 15.7 & 15.9 & \\
\hline & Mistiaen 2010 & 18.2 & 18.1 & \\
\hline & Pooled data & 16.2 & 16.3 & 0.49 \\
\hline \multirow{4}{*}{$\begin{array}{l}\text { Mean number of days } \\
\text { of observation }\end{array}$} & McGowan 2000 & 10.6 & 10.7 & \\
\hline & Jolley 2004 & 7.9 & 7.0 & \\
\hline & Mistiaen 2010 & 27.9 & 27.7 & \\
\hline & Pooled data & 16.9 & 16.6 & 0.59 \\
\hline \multirow{4}{*}{$\begin{array}{l}\text { Total number of days } \\
\text { of observation }\end{array}$} & McGowan 2000 & 1635 & 1513 & \\
\hline & Jolley 2004 & 1728 & 1561 & \\
\hline & Mistiaen 2010 & 7549 & 7510 & \\
\hline & Pooled data & 10912 & 10584 & \\
\hline
\end{tabular}


Mistiaen, P.J., Jolley, D.J., McGowan, S., Hickey, M.B., Spreeuwenberg, P., Francke, A.L. A multilevel analysjs of three randomised controlled trials of the Australian Medical Sheepskin in the prevention of sacral pressyr ulcers. Medical Journal of Australia: 2010, 193(11/12), 638-641

4 Incidence of sacral pressure ulcers (PUs) and results from analyses of data from three randomised controlled trials of the Australian Medical Sheepskin

$\frac{\text { Intervention group }}{\text { No. of PUs }} \frac{\text { Control group }}{\text { No. of PUs }} \frac{\text { Odds ratio }(95 \% \mathrm{Cl})}{\text { Conventional Multilevel }}$

Study (grade 1, 2, 3, 4) Patients (grade 1, 2, 3, 4) Patients meta-analysis* analysis ${ }^{\dagger}$

\begin{tabular}{lcccccc}
\hline $\begin{array}{l}\text { McGowan } \\
2000^{14}\end{array}$ & $4(4,0,0,0)$ & 155 & $22(20,2,0,0)$ & 142 & $0.14(0.05-0.43)$ & $0.14(0.04-0.43)$ \\
$\begin{array}{l}\text { Jolley } \\
2004^{15}\end{array}$ & $7(5,2,0,0)$ & 218 & $16(13,3,0,0)$ & 223 & $0.43(0.17-1.06)$ & $0.32(0.12-0.85)$ \\
$\begin{array}{l}\text { Mistiaen } \\
2010^{16}\end{array}$ & $24(18,6,0,0)$ & 271 & $40(32,6,2,0)$ & 272 & $0.56(0.33-0.96)$ & $0.53(0.29-0.95)$ \\
Overall & $35(27,8,0,0)$ & 644 & $78(65,11,2,0)$ & 637 & $0.37(0.17-0.77)$ & $0.35(0.23-0.55)$ \\
\hline
\end{tabular}

* Pooled published effect sizes. † Pooled individual patient data.

5 Conventional and multilevel analyses of pooled data from three randomised controlled trials of the Australian Medical Sheepskin
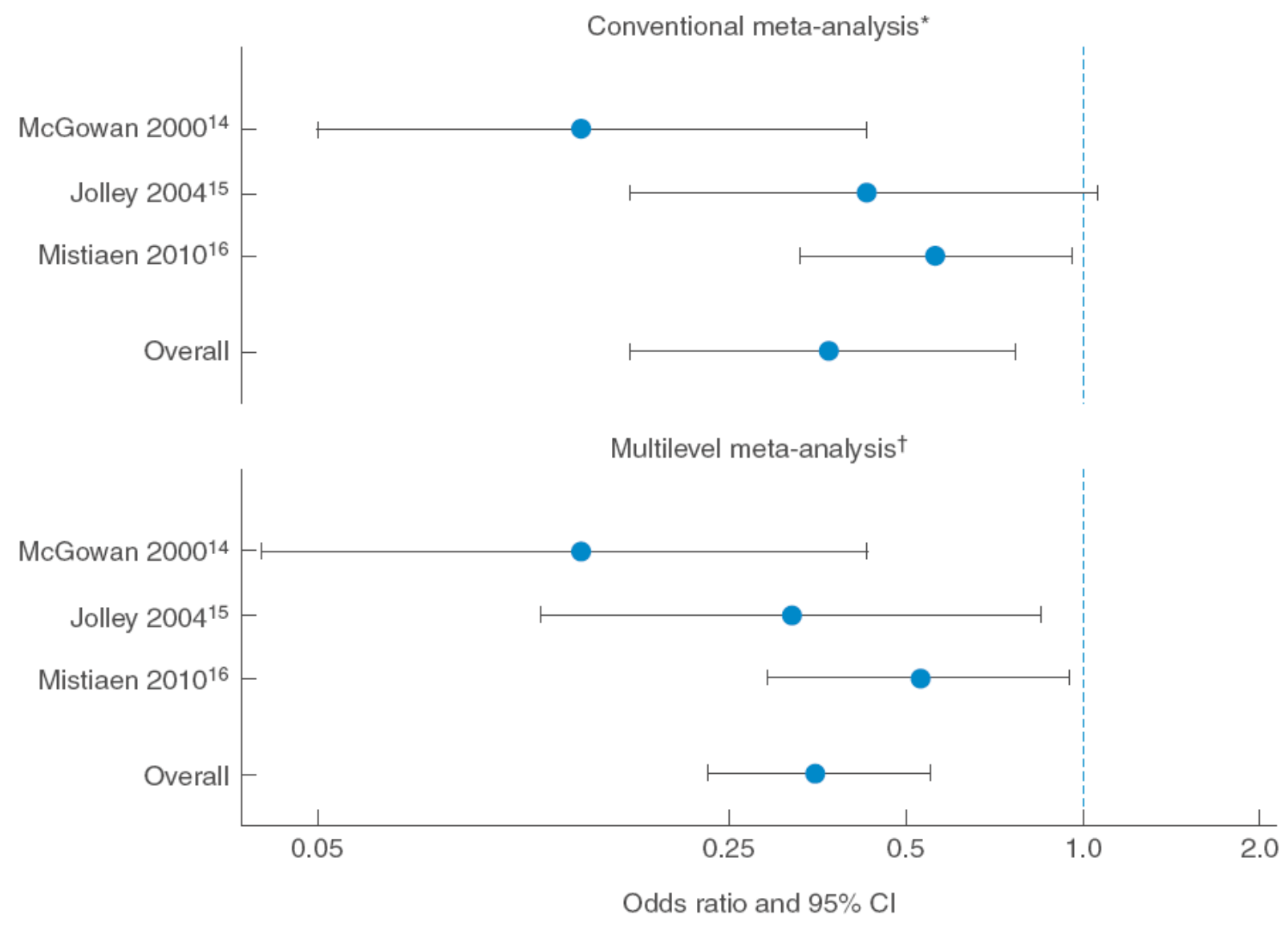

* Pooled published effect sizes. † Pooled individual patient data. 